Article

\title{
Feasibility of Harvesting Solar Energy for Self-Powered Environmental Wireless Sensor Nodes
}

\author{
Yuyang Li ${ }^{1,+}$, Ehab A. Hamed ${ }^{1,+}$, Xincheng Zhang ${ }^{1}$, Daniel Luna ${ }^{2}{ }^{\oplus}$, Jeen-Shang Lin ${ }^{2}$, \\ Xu Liang ${ }^{2}$ and Inhee Lee ${ }^{1, * \text { iD }}$ \\ 1 Department of Electrical and Computer Engineering, University of Pittsburgh, Pittsburgh, PA 15261, USA; \\ yul230@pitt.edu (Y.L.); ehab.hamed@pitt.edu (E.A.H.); xiz193@pitt.edu (X.Z.) \\ 2 Department of Civil and Environmental Engineering, University of Pittsburgh, Pittsburgh, PA 15261, USA; \\ del47@pitt.edu (D.L.); jslin@pitt.edu (J.-S.L.); xuliang@pitt.edu (X.L.) \\ * Correspondence: inhee.lee@pitt.edu \\ + These authors contributed equally to this work.
}

Received: 5 November 2020; Accepted: 30 November 2020; Published: 3 December 2020

check for updates

\begin{abstract}
Energy harvesting has a vital role in building reliable Environmental Wireless Sensor Networks (EWSNs), without needing to replace a discharged battery. Solar energy is one of the main renewable energy sources that can be used to efficiently charge a battery. This paper introduces two solar energy harvesters and their power measurements at different light conditions in order to charge rechargeable AA batteries powering EWSN nodes. The first harvester is a primitive energy harvesting circuit that is built using elementary off-shelf components, while the second harvester is based on a commercial boost converter chip. To prove the effectiveness of harvesting solar energy, five EWSN nodes were distributed at a nature reserve (the Audubon Society of Western Pennsylvania, USA) and the sunlight at their locations was recorded for more than five months. For each recorded illumination, the corresponding harvested energy has been estimated and compared with the average energy consumption of the EWSN with the most power consumption. The results show that the daily harvested energy effectively compensates for the energy consumption of the EWSN nodes, and the battery charge capacity of $295 \mathrm{mAh}$ can reliably support their daily dynamic energy consumption.
\end{abstract}

Keywords: batteries; energy harvesting; environmental monitoring; illumination; solar energy; sunlight; wireless sensor networks (WSNs)

\section{Introduction}

Wireless Sensor Networks (WSNs) have extensive popularity in the field of environmental monitoring [1-5]. Recently, an Environmental Wireless Sensor Network (EWSN) has been exceptionally enhanced due to the development of the Internet of Things (IoT) [6]. EWSN nodes are deployed in open areas (e.g., forests); accordingly, they are not connected to the main power supply because of high wiring cost and difficulty. Instead, an EWSN node usually depends on a rechargeable or non-rechargeable battery to operate; while a non-rechargeable battery requires regular replacement, a rechargeable battery can be recharged by energy harvesting and thus more reliable and effective in the long-term cost [6]. A high capacity battery can be used to lengthen the period of successive replacement or recharging, but it typically increases the node size and weight $[7,8]$. Alternatively, an energy harvester can be utilized to scavenge the surrounding ambient energy (such as heat, electromagnetic, motion, and light energy) and convert it to electrical energy that charges a battery and thus powers an EWSN node $[9,10]$.

Efficient conversion from ambient energy to electrical energy is crucial for a practical energy harvester. Conversion from thermal energy to electrical energy is established based on the Seebeck 
effect $[6,9,11-16]$, which depends on the temperature difference between pairs of $p$-type and $n$-type semiconductor plates. The thermoelectric conversion has low efficiency because it is limited by Carnot cycle efficiency $[9,15,17]$, and the conversion process stops at stable heat when both plates settle at the same temperature [6,18-20]. On the other hand, the ambient Radio Frequency (RF) signals (radar, Wi-Fi, Bluetooth, and cellular networks [9,21-23]) are sources of electromagnetic energy that can be harvested and converted to electrical energy. The widespread existence of RF signals and their vast frequency range make them appropriate for powering numerous WSN nodes in a large area. Nevertheless, the harvested energy greatly varies according to the distance between the node and RF source $[9,24]$.

The fact that EWSN nodes are deployed in a natural environment makes them subject to wind and sunlight. The kinetic energy of wind can be converted to electrical energy using turbines or rotors, giving high harvested power $[6,25,26]$. However, harvesting wind energy requires large wind turbines, and sometimes the wind is neither available nor predictable [6]. Alternatively, sunlight is a remarkable renewable source of energy that can be harvested effectively [6,27], using photovoltaic solar cells that convert solar energy to electrical energy $[1,28]$. Solar cells are connected in series and parallel, forming modules or solar panels, to increase the total harvested power [6]. In addition to solar cell size, the solar energy obtained from the sun is also proportional to the illumination level, which is inconstant and varies according to time, region, and weather [6,29]. Therefore, a rechargeable battery is often included with a solar energy harvester to store the solar energy in the chemical form [9,30,31]. It is used to power the EWSN nodes when the light source is unavailable. Figure 1 shows an overview of the solar energy harvesting process starting from the solar panel and ending with the EWSN node. Solar energy cannot be controlled, but it is predictable during the day and seasons [6,32]. To keep a node battery from energy depletion, the average energy consumption of an EWSN node must not surpass the average harvested energy from the sun [6].

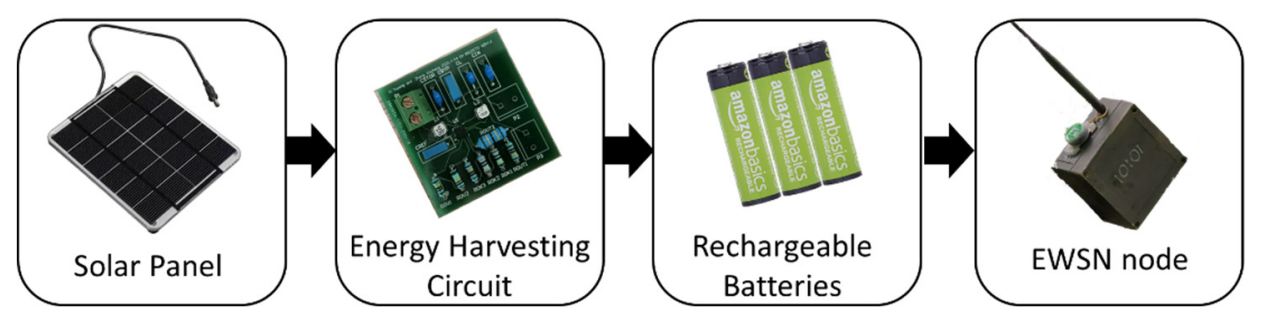

Figure 1. Solar energy harvesting process for the target application.

In this work, we propose two energy harvesters to avoid the battery replacement of the ESWN nodes. The first harvester is a primitive energy harvesting circuit that is built using elementary off-shelf components, while the second harvester is based on a commercial boost converter chip. They are designed using commercially available components so that the harvester design can be rapidly applied to similar applications. Moreover, the effectiveness of the harvester is verified by using light intensity measurement on the exemplary EWSN nodes [7,33-35] in a nature reserve (Audubon Society of Western Pennsylvania, USA) for 5 months. Based on the measured light profile and harvesting efficiency, it is estimated that both harvesters are able to compensate for the energy consumption of the EWSN nodes. A battery with a maximum charge capacity of 295 milliampere-hour (mAh) can reliably support the daily dynamic energy consumption of the EWSN node. Moreover, we find that the primitive energy harvester can cost at least USD 10 less than the second harvester. However, the primitive energy harvester provides degraded battery charging ability when light intensity becomes less than 1 kilolux (klx) due to a significant harvesting efficiency drop under weak light.

The rest of the article is organized as follows: Section 2 describes the primitive solar energy harvester and component selection; Section 3 introduces the utilization of bq25570 chip in harvesting solar energy and how to determine the values of its external passive components; Section 4 presents the measured light intensities at the deployed nodes and shows the generated current from the solar 
harvesters and the estimated remaining charge in the battery, then it discusses the important results. Finally, Section 5 concludes the paper.

\section{Primitive Solar Energy Harvester}

The proposed primitive solar energy harvester is attractive by its low cost, as it mainly consists of only two cheap off-shelf components (nMOS transistor and diode), as shown in Figure 2, making it a good production choice to serve for a large number of WSN nodes. The harvester circuit is connected to a solar panel as a source for input power and rechargeable batteries as a charge destination. This circuit has two tasks: the first is to stop charging the batteries after reaching their maximum voltage to protect the load circuits from being damaged, and the second is to prevent the batteries from being discharged through the leakage current of the harvesting circuit. For testing purposes, Keithley 2400 SourceMeters are used to measure the voltage and current of the batteries and turn on/off the nMOS transistor. In reality, the EWSN node measures battery voltage and provides the switching digital signal that indicates the full charge of the batteries. The nMOS transistor short-circuits the solar panel and stops harvesting when the battery voltage $\left(\mathrm{V}_{\mathrm{BAT}}\right)$ exceeds 3.6 Voltage $(\mathrm{V})$, which is the nominal operating voltage of three 1.2 V NiMH AA batteries connected in series. The leakage current of the nMOS transistor has to be a minimum to avoid unwanted loss from the harvested energy through it. Table 1 shows the measurement results of two samples of three transistor models (TN5325N3, BS270FS, and ZVN2110A) at a battery voltage of $3.6 \mathrm{~V}$ and illumination of $100 \mathrm{klx}$. Their leakage current does not exceed 0.5 nanoampere (nA), which is negligible compared with the average current consumption of the target EWSN node. ZVN2110A is selected for the proposed harvester design since it has the minimum leakage current with a small variation.

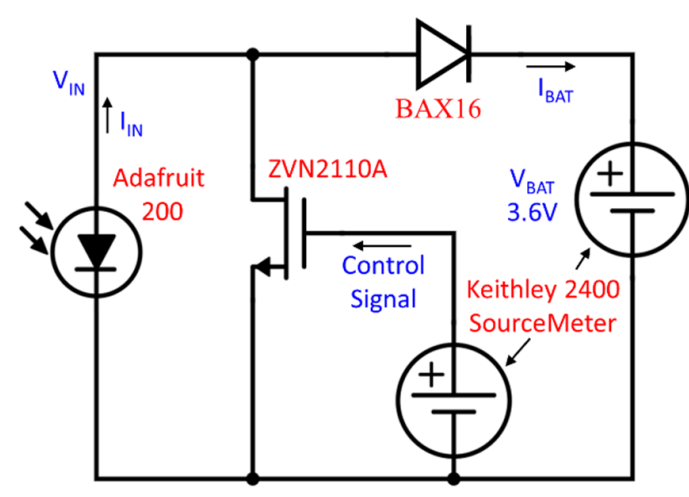

(a)

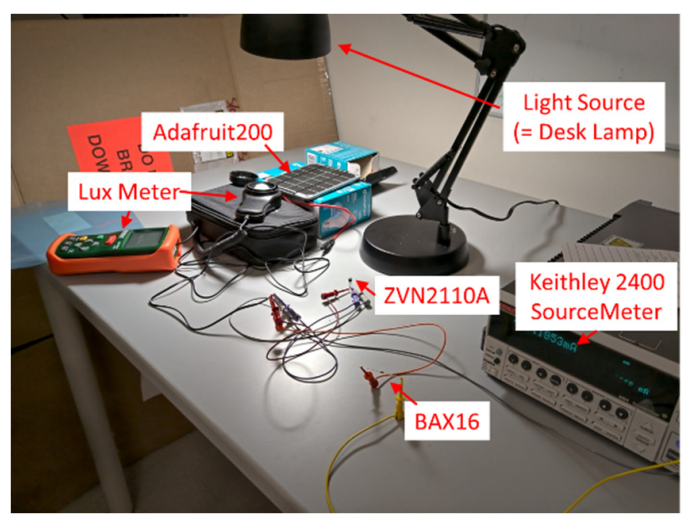

(b)

Figure 2. Primitive solar energy harvester. (a) Circuit diagram of the harvester. (b) Testbench of power measurements.

Table 1. Measured leakage current of nMOS transistors at $100 \mathrm{klx}$ and $\mathrm{V}_{\mathrm{BAT}}=3.6 \mathrm{~V}$.

\begin{tabular}{ccc}
\hline \multirow{2}{*}{ Model } & \multicolumn{2}{c}{ Leakage Current (pA) } \\
\cline { 2 - 3 } & 1st Sample & 2nd Sample \\
\hline TN5325N3 & 300 & 400 \\
\hline BS270FS & 20 & 300 \\
\hline ZVN2110A & 30 & 30 \\
\hline
\end{tabular}

The diode prevents the batteries from being discharged by the harvesting circuit at weak light conditions. It needs to have a low voltage drop and leakage current since the diode voltage drop decreases the minimum light intensity to recharge the battery, and the diode leakage current reduces 
battery charging current. Table 2 shows the measurement results of two samples from four diode models (BAX16, 1N4148FS, 1N4149, and FDH333) at a battery voltage of $3.6 \mathrm{~V}$. The diode voltage drops are measured at three different lighting conditions such as $1 \mathrm{klx}, 10 \mathrm{klx}$, and $100 \mathrm{klx}$, and the leakage currents are measured at $100 \mathrm{klx}$. The leakage currents of all diodes are negligible $(<5 \mathrm{nA})$. BAX16 is selected for the proposed harvester due to the lowest voltage drop.

Table 2. Measured leakage current and voltage drop of four diode models (two units for each model) at different light conditions and $\mathrm{V}_{\mathrm{BAT}}=3.6 \mathrm{~V}$.

\begin{tabular}{ccccc}
\hline \multirow{2}{*}{ Model } & \multicolumn{3}{c}{ Voltage Drop (V) } & $\mathbf{I}_{\text {leakage }}$ (nA) \\
\cline { 2 - 5 } & $\mathbf{1 ~ k l x}$ & $\mathbf{1 0 ~ k l x}$ & $\mathbf{1 0 0} \mathbf{~ k l x}$ & $\mathbf{1 0 0} \mathbf{~ k l x}$ \\
\hline BAX16 & $0.59 / 0.58$ & $0.72 / 0.71$ & $0.82 / 0.81$ & $4.72 / 3.78$ \\
\hline 1N4148FS & $0.62 / 0.61$ & $0.73 / 0.73$ & $0.82 / 0.82$ & $3.12 / 3.03$ \\
\hline 1N4149 & $0.62 / 0.61$ & $0.73 / 0.73$ & $0.82 / 0.82$ & $2.92 / 2.79$ \\
\hline FDH333 & $0.68 / 0.68$ & $0.79 / 0.79$ & $0.85 / 0.85$ & $0.03 / 0.03$ \\
\hline
\end{tabular}

Figure 3 shows the measured output power of the proposed primitive harvester with four solar panels (SM531K80L, Adafruit200, LL200-3-37 (Serial), and LL200-3-37 (Parallel)) at different light conditions ( $1 \mathrm{klx}, 10 \mathrm{klx}$, and $100 \mathrm{klx})$. SM531K80L has the highest output power at $100 \mathrm{klx}$ for $3.6 \mathrm{~V}$. However, it produces lower output power than other panels at weaker light conditions. On the other hand, Adafruit200 has appropriate output power around 3.6 V battery voltage for a wide range of light conditions, which makes it a good choice to feed the harvester circuit.

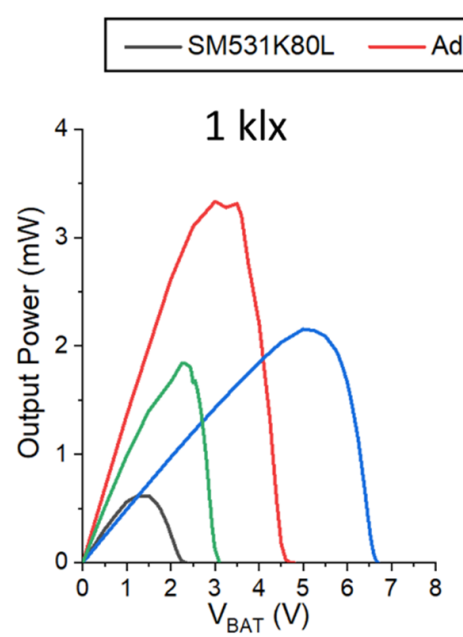

(a)

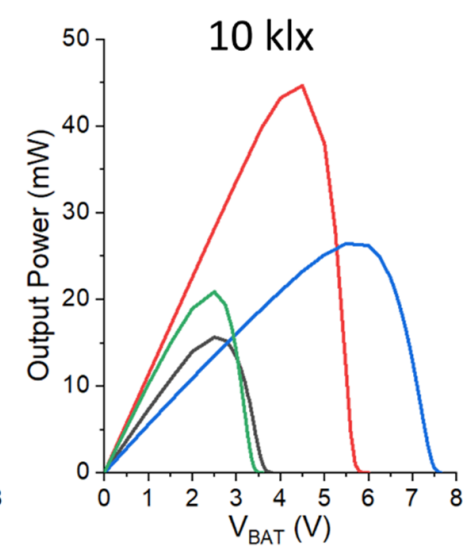

(b)

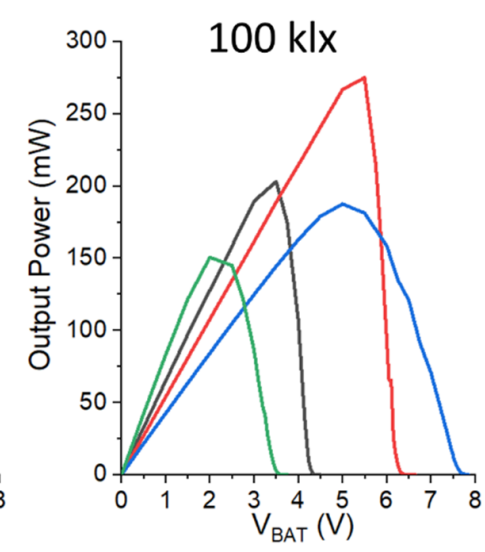

(c)

Figure 3. Measured output power of the primitive harvester circuit with four different solar panels at different light conditions: (a) 1 klx; (b) $10 \mathrm{klx}$; (c) $100 \mathrm{klx}$.

\section{Solar Energy Harvester Based on bq25570 IC}

The Bq25570 chip from Texas Instruments is a device that integrates energy harvesting and power managing. The chip is designed to efficiently extract low power in the range of microwatts to milliwatts. Moreover, bq25570 provides overcharge protection for batteries and buck converter for output regulation. Moreover, it has a programmable maximum power point tracking (MPPT) module which optimizes the energy extraction from different sources (such as solar panels), while the chip itself consumes only hundreds of nano amperes current [36]. According to the advantages, bq25570 has been utilized as a solution to recharge the batteries of the EWSN nodes, which can be compared with the primitive harvester for performance comparison. 
Figure 4 shows the energy harvester circuit utilizing bq25570. External resistors are used to determine voltages necessary for required operations for the bq25570. First, the bq25570 uses the harvested current to charge CSTOR until its voltage exceeds the under-voltage (UV) threshold which is internally set to $\sim 1.95 \mathrm{~V}$. Then, the transistor between VSTOR and VBAT is turned on, and the battery begins to be charged. The battery over-voltage $(\mathrm{OV})$ protection threshold is set using $\mathrm{R}_{\mathrm{OV} 1}$ and $\mathrm{R}_{\mathrm{OV} 2}$ according to the following equation [36]. When the battery voltage exceeds this value (VBAT_OV), the connection from the input to the VSTOR is turned off to stop charging the $\mathrm{C}_{\mathrm{STOR}}$ and the battery.

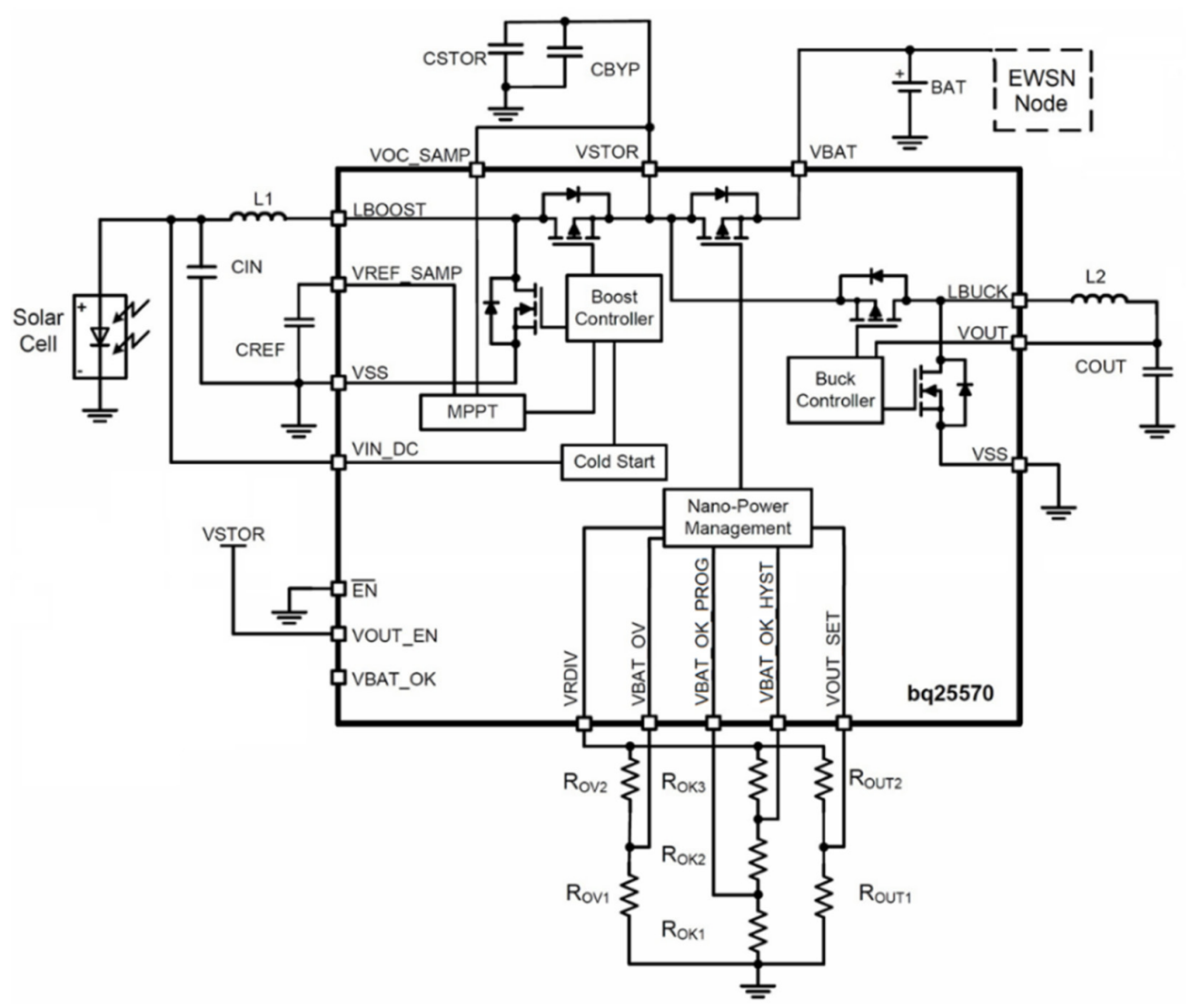

(a)

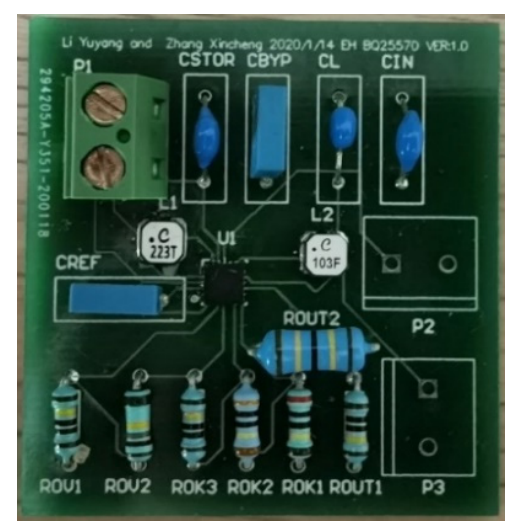

(b)

Figure 4. Energy harvester based on bq25570. (b) Designed harvester.

(a) Circuit diagram (modified from [36]). 


$$
V B A T \_O V=\frac{3}{2} V_{B I A S}\left(1+\frac{R_{O V 2}}{R_{O V 1}}\right) .
$$

here, $V_{B I A S}$ nominal value is $1.21 \mathrm{~V} . R_{O V 1}$ and $R_{O V 2}$ are chosen to be 1 and 1.05 megaohm $(\mathrm{M} \Omega)$, respectively, to limit the over-voltage (VBAT_OV) to $3.72 \mathrm{~V}$. Similar to the over-voltage threshold, the operating range of the battery voltage has to be independently programmed between 3 and $3.6 \mathrm{~V}$ using the following equations [36].

$$
\begin{gathered}
V B A T \_O K \_P R O G=V_{B I A S}\left(1+\frac{R_{O K 2}}{R_{O K 1}}\right) . \\
V B A T \_O K \_H Y S T=V_{B I A S}\left(1+\frac{R_{O K 2}+R_{O K 3}}{R_{O K 1}}\right) .
\end{gathered}
$$

here, VBAT_OK_PROG is the lower threshold for the battery, and VBAT_OK_HYST is its upper threshold. $R_{O K 1}, R_{O K 2}$, and $R_{O K 3}$ are chosen to be 2,3 , and $1 \mathrm{M} \Omega$, respectively. The buck converter is designed to give $2.9 \mathrm{~V}$ output voltage according to the following equation [36], by selecting $R_{\text {OUT1 }}$ and $R_{\text {OUT2 }}$ to be 1 and $1.4 \mathrm{M} \Omega$, respectively. However, for a fair comparison between the primitive harvester and bq25570-based harvester, the EWSN node in this work is connected directly to the battery and no current is absorbed from the buck converter.

$$
\text { VOUT }=V_{\text {BIAS }}\left(\frac{R_{\text {OUT1 }}+R_{\text {OUT2 }}}{R_{\text {OUT1 }}}\right)
$$

Table 3 shows the values of all the selected resistors and their corresponding voltages. CREF, CIN, CSTOR, CBYP, COUT, L1, and L2 are chosen to be 10 nanofarad $(\mathrm{nF}), 4.7$ microfarad $(\mu \mathrm{F}), 4.7 \mu \mathrm{F}, 10 \mathrm{nF}$,

\begin{tabular}{|c|c|c|c|}
\hline \multicolumn{2}{|c|}{ Actual Resistors } & \multicolumn{2}{|c|}{ Corresponding Voltages } \\
\hline Rov1 & $1.00 \mathrm{M} \Omega$ & \multirow{2}{*}{ VBAT_OV } & \multirow{2}{*}{$3.72 \mathrm{~V}$} \\
\hline $\mathrm{R}_{\mathrm{OV} 2}$ & $1.05 \mathrm{M} \Omega$ & & \\
\hline $\mathrm{R}_{\mathrm{OK} 1}$ & $2.00 \mathrm{M} \Omega$ & \multirow{3}{*}{$\begin{array}{c}\text { VBAT_OK } \\
\text { VBAT_OK_HYST }\end{array}$} & \multirow{3}{*}{$\begin{array}{l}3.03 \mathrm{~V} \\
3.63 \mathrm{~V}\end{array}$} \\
\hline $\mathrm{R}_{\mathrm{OK} 2}$ & $3.00 \mathrm{M} \Omega$ & & \\
\hline $\mathrm{R}_{\mathrm{OK} 3}$ & $1.00 \mathrm{M} \Omega$ & & \\
\hline $\mathrm{R}_{\text {OUT1 }}$ & $1.00 \mathrm{M} \Omega$ & \multirow{2}{*}{ VOUT } & \multirow{2}{*}{$2.90 \mathrm{~V}$} \\
\hline $\mathrm{R}_{\text {OUT2 }}$ & $1.40 \mathrm{M} \Omega$ & & \\
\hline
\end{tabular}
$22 \mu \mathrm{F}, 22$ microhenry $(\mu \mathrm{H})$, and $10 \mu \mathrm{H}$, respectively [36]. The maximum power point threshold is set to $80 \%$ of the open-circuit voltage of the solar cell.

Table 3. External resistors are used to set up the bq25570 and their corresponding voltages.

\section{Measurement Results}

The target EWSN nodes are developed based on IRIS [37] and MicaZ [38-40] motes [7]. The motes are connected to MDA300 data acquisition board [41] to measure temperature and humidity. Moreover, the acquisition board digitizes analog signals from three external soil moisture sensors [7], using its analog-to-digital converter. Operating on TinyOS 2.1.2, the nodes sample sensor data packets every $15 \mathrm{~min}$, including measured temperature, humidity, and soil moisture data. The EWSN nodes are classified to relay nodes that improve network connectivity without operating external sensors, and regular nodes with fixed locations and external sensors [7]. Thus, there are four different nodes, namely, relay nodes based on the IRIS platform, relay nodes based on the MicaZ platform, regular nodes based on the IRIS platform with three soil moisture sensors, and regular nodes based on the MicaZ platform with three soil moisture sensors. Table 4 shows the current consumption and duration for different operation of the nodes. The most power-hungry node was the regular node 
based on the MicaZ platform, which has a charge consumption rate of 120,978 milliampere-second $(\mathrm{mAs}) /$ day. Considering a $5 \%$ margin, $127,026 \mathrm{mAs} /$ day is used to check the feasibility of the proposed energy harvesters.

Table 4. Current consumption of the target nodes [7].

\begin{tabular}{ccccc}
\hline & \multicolumn{2}{c}{ IRIS } & \multicolumn{2}{c}{ MicaZ } \\
\cline { 2 - 5 } Operation & $\begin{array}{c}\text { Current } \\
\text { Consumption } \\
(\mathbf{m A})\end{array}$ & Duration (ms) & $\begin{array}{c}\text { Current } \\
\text { Consumption } \\
\mathbf{( m A )}\end{array}$ & Duration (ms) \\
\hline $\begin{array}{c}\text { Sensor Sampling w/o } \\
\text { external sensors }\end{array}$ & 6.3 & 341.8 & 6.8 & 337.0 \\
\hline $\begin{array}{c}\text { Sensor Sampling } \\
\text { w/external sensors }\end{array}$ & 59.1 & 341.8 & 91.8 & 337.0 \\
\hline Data Packet Transmission & 6.5 & 1.5 & 9.2 & 2.4 \\
\hline Data Packet Reception & 21.1 & 23.6 & 22.7 & 24.0 \\
\hline Idle Listening & 19.1 & 5.4 & 23.3 & 3.7 \\
\hline Sleep (Relay/Reg.) & $0.1 / 1.0$ & N/A & $0.3 / 1.1$ & N/A \\
\hline
\end{tabular}

The EWSN notes have a supply voltage operating range between 2.7 and $3.6 \mathrm{~V}$ [7]. It can be provided by connecting three $1.2 \mathrm{~V}$ batteries in series. Considering AmazonBasics 1.2V NiMH AA rechargeable batteries ( $2000 \mathrm{mAh}$ ), the battery voltage mainly stays at $3.6 \mathrm{~V}$ by energy harvesting, which will be clear at the end of this section. Figure 5 shows the harvested current and the end-to-end efficiency of the primitive harvester and the bq25570-based harvester at 3.6 V across light intensities.

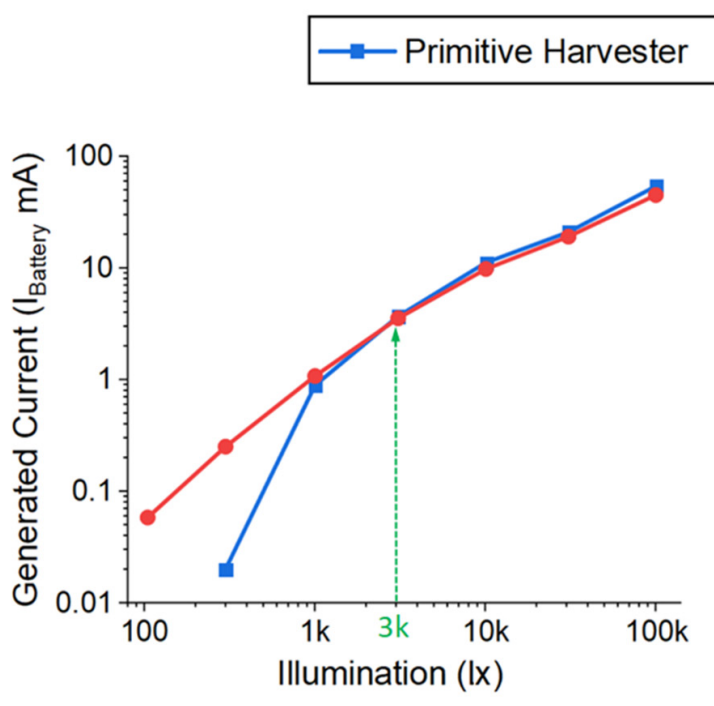

(a)

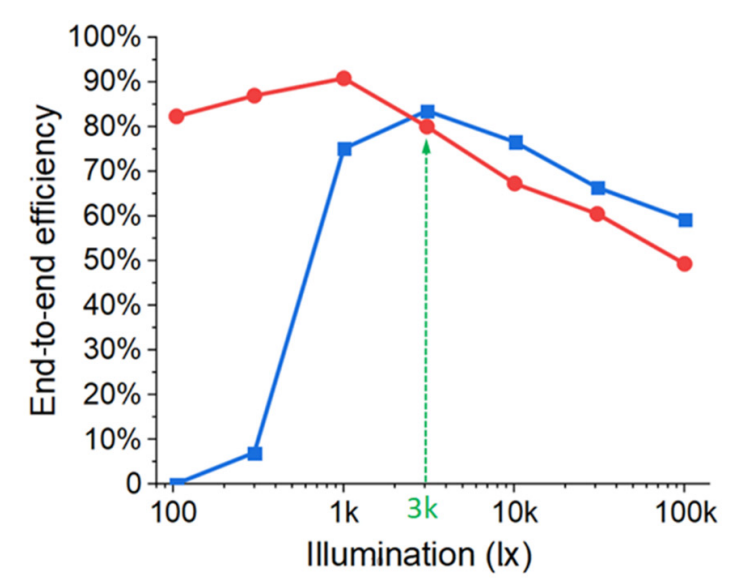

(b)

Figure 5. Measured energy harvesters with different illuminations: (a) generated current; (b) end-to-end efficiency.

To judge the feasibility of the proposed energy harvesters, we take the advantage of the outdoor multi-hop EWSN by the University of Pittsburgh and Indiana University Purdue University Indianapolis (IUPUI) (https://sites.google.com/site/aswpitt/) located inside the Beechwood Farms Nature Reserve of Audubon Society of Western Pennsylvania in the greater Pittsburgh area [35]. The reserve is densely wooded with varying stages of mixed deciduous forest, an old conifer plantation, clear meadows, shrubland and wetland vegetation (http://www.aswp.org/pages/beechwood). As shown in Figure 6, 
we recorded the illuminations of sunlight on the EWSN nodes with the goal that the surrounding diverse plant community will enable the study results to have wide applications.

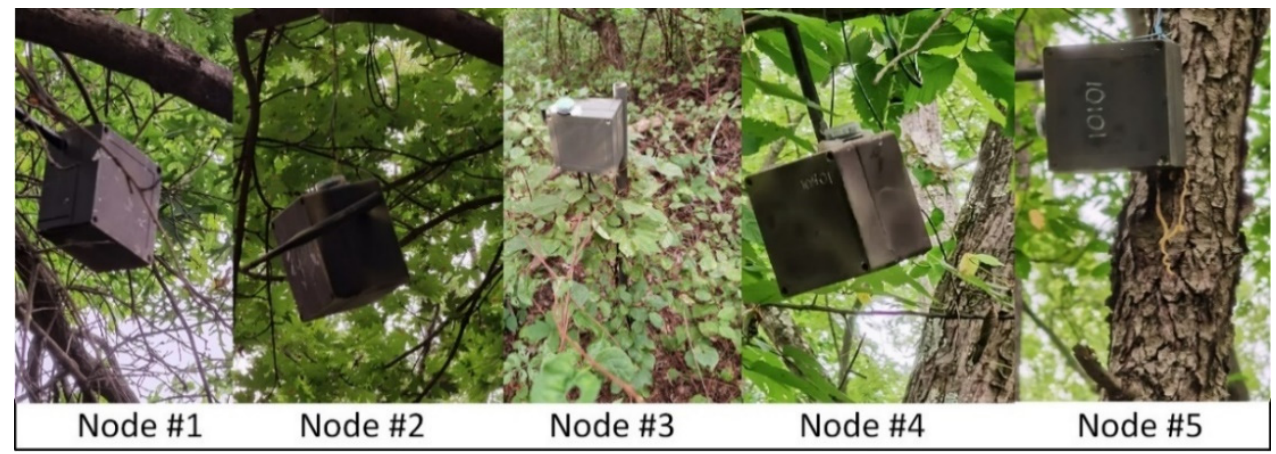

Figure 6. 5 EWSN nodes with MX2202 light sensors.

HOBO Pendant MX loggers (MX2202) are attached to each node and collect light intensities every 5 min for more than 5 months (11/2/2019-4/17/2020). Figure 7 plots the measured light intensities from the MX2202 for Nodes \#1 and \#5 as examples. The measured light intensities are different since the orientation of the nodes and the shade conditions by trunks, branches, and leaves are different.

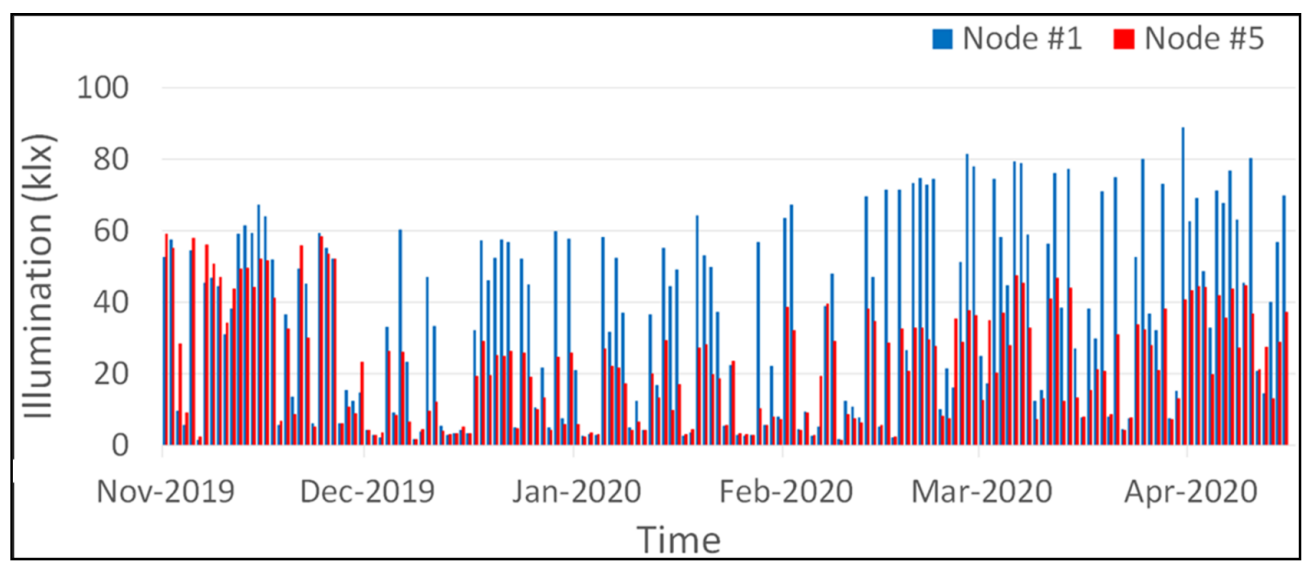

Figure 7. Measured light intensity using MX2202 light sensors at two nodes (\#1 and \#5).

Figure 8a shows the calculated harvested current, at Node \#5 with the weakest light condition among the five nodes, for the primitive harvester in the blue line and the bq25570-based harvester in the red line, based on measurement results of the harvester itself (Figure 5) and environment light intensity (Figure 7). Figure $8 b, c$ show the predicted remaining charge of the batteries every $5 \mathrm{~min}$. The remaining charge is predicated by adding the estimated harvested charge ('generated current' $\times 5 \mathrm{~min}$ ) and subtracting the average charge consumption of $0.125 \mathrm{mAh}$ every $5 \mathrm{~min}$. However, it takes into consideration that the battery charge does not exceed the maximum capacity of $2000 \mathrm{mAh}$. The remaining charge is different among the nodes since light intensities are different, as shown in Figure 7 with the examples of Nodes \#1 and \#5.

The important results from Figures 7 and 8 for both harvesters (primitive and bq25570-based harvesters) are summarized in Table 5, showing the average and maximum illumination of the light, the average and maximum estimated charging currents, and the estimated minimum remaining battery charge. All the tabulated numbers are calculated for the five deployed nodes from November 2019 to the middle of April 2020. The average and maximum illumination values cannot indicate directly to the most efficient harvested energy. Node \#1 has the highest maximum illumination and maximum charging current, while Node \#2 has the highest average illumination and average charging current; 
nevertheless, Node \#3 shows the highest minimum required charge, which makes it the most efficient node in exploiting the harvested solar energy. This observation validates the idea that the existence of light over a long period of each day is more important than its maximum or average intensity since the battery cannot acquire a charge over its maximum capacity.

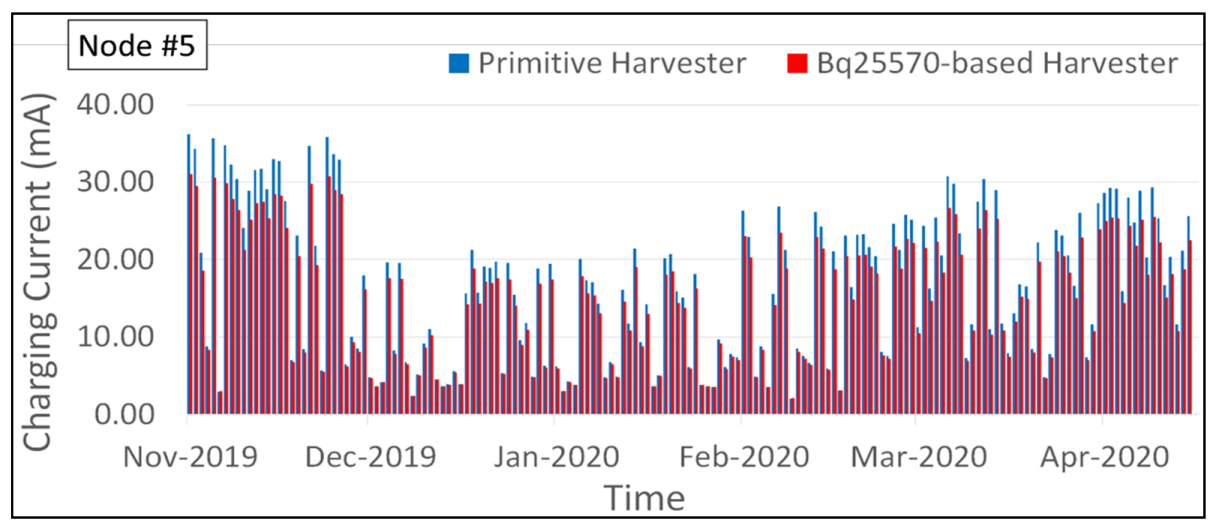

(a)

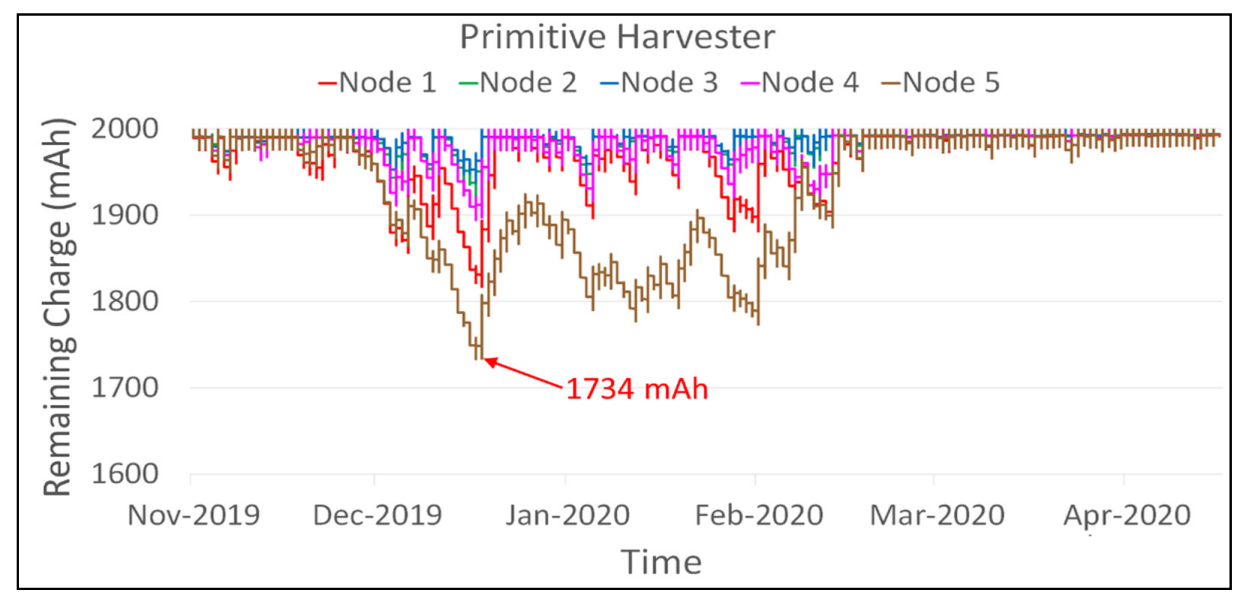

(b)

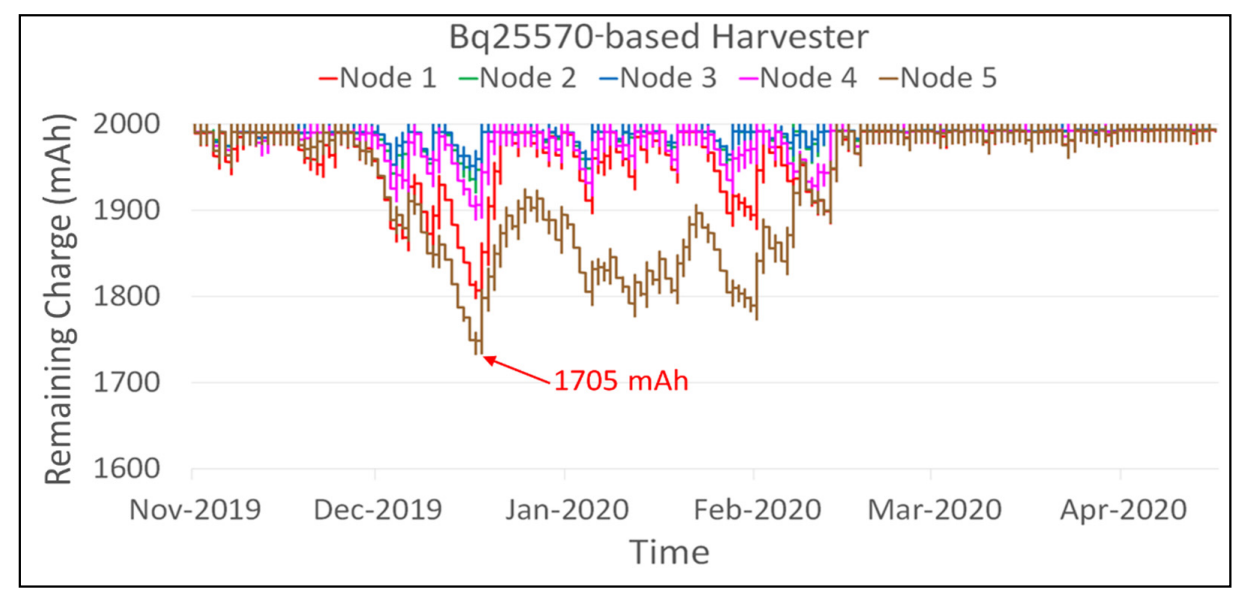

(c)

Figure 8. Estimated battery charging current and remaining charge. (a) Estimated charging current at node 5 for both harvesters. (b) Estimated batteries remaining charge for the primitive energy harvester. (c) Estimated batteries remaining charge for the bq25570-based energy harvester. 
Table 5. Summary of the most important readings in the measured and estimated data for both harvesters at the five nodes over more than 5 months.

\begin{tabular}{ccccccccc}
\hline \multirow{2}{*}{ Node } & \multicolumn{2}{c}{ Illumination (Lux) } & \multicolumn{2}{c}{$\begin{array}{c}\text { Avg. Charging } \\
\text { Current (mA) }\end{array}$} & \multicolumn{2}{c}{$\begin{array}{c}\text { Max. Charging } \\
\text { Current (mA) }\end{array}$} & \multicolumn{2}{c}{$\begin{array}{c}\text { Min. Remaining } \\
\text { Battery Charge (mAh) }\end{array}$} \\
\cline { 2 - 9 } & Avg. & Max & Primitive & Bq25570 & Primitive & Bq25570 & Primitive & Bq25570 \\
\hline$\# 1$ & 3161 & 88,760 & 2.61 & 2.42 & 49.0 & 41.1 & 1818 & 1793 \\
\hline$\# 2$ & 4814 & 85,852 & 3.86 & 3.54 & 47.8 & 40.1 & 1923 & 1921 \\
\hline$\# 3$ & 3969 & 75,796 & 3.38 & 3.13 & 43.5 & 36.8 & 1938 & 1937 \\
\hline$\# 4$ & 3627 & 77,087 & 3.05 & 2.83 & 44.1 & 37.2 & 1895 & 1890 \\
\hline$\# 5$ & 2505 & 59,105 & 2.27 & 2.14 & 36.1 & 31.0 & 1734 & 1705 \\
\hline
\end{tabular}

Both harvesters are estimated to continuously power any of the five nodes at the given $2000 \mathrm{mAh}$ batteries without a power outage. The difference in the remaining charge is slightly better in the primitive harvester, the batteries charge drops from 2000 to $1734 \mathrm{mAh}$ before starting to recharge again, while, for the bq25570-based harvester, the batteries charge drops to $1705 \mathrm{mAh}$. It makes the battery charge not to drop below $85 \%$ of its maximum charge capacity for both harvesters. Moreover, the average charging current from all harvesters is above $2 \mathrm{~mA}$, which is higher than the average current consumption of $1.5 \mathrm{~mA}$ by the most power-hungry node in [7]. It keeps the batteries charged and thus ensures the ability of both harvesters to continuously power the nodes.

In this work, the AA batteries have been considered to replace the non-rechargeable battery used in [7]. Since the batteries support enough charge storage capability in the given illumination profile, smaller size of batteries with lower maximum charge capacity can be applied. For example, an AmazonBasics 1.2 V NiMH AAA rechargeable battery has the maximum charge capacity of $800 \mathrm{mAh}$ with the same output voltage. The three batteries reduce the volume from 23,088 cubic millimeters $\left(\mathrm{mm}^{3}\right)$ to $11,559 \mathrm{~mm}^{3}$ (50\% lower) and the price for three batteries from USD 4.5 to USD 3.2 (29\% lower) while maintaining the remaining charge higher than $63 \%$. However, the smaller remaining charge makes the battery output voltage lower in general so that the efficiency of the primitive harvester can be reduced as shown in Figure 3b,c. In addition, if environmental light intensity is unexpectedly weaker than the exemplary light profile, the node with smaller batteries can experience power outage due to the reduced energy margin stored in the batteries.

Moreover, different types of batteries can be applied, such as a lithium coin battery or lithium polymer batteries, to further reduce the physical battery volume with a commercially available option. For instance, as an extreme case with negligible remaining charge capacity, an Illinois Capacitor RJD3048 3.7 V lithium coin battery (300 mAh) and a Jauch LP422339JU1s1p 3.7 V lithium polymer battery ( $330 \mathrm{mAh}$ ) only take a volume of 3393 and $4324 \mathrm{~mm}^{3}$, respectively. However, the high battery voltage cannot be applied to the nodes directly. It is required to add a voltage regulator between the battery and the node, increasing design complexity.

The primitive harvester only has two components, and the total cost of the harvester circuit does not exceed USD 1 excluding the solar panel. The ZVN2110A nMOS transistor costs USD 0.68, and the BAX16 diode costs USD 0.19. On the other hand, the cost of bq25570 IC alone is USD 7.7. The cost becomes easily beyond USD 10 by considering other discrete components to build a complete bq25570-based harvester circuit. It makes the total cost at least USD 10 higher than that of the primitive harvester. However, Figure 5 shows that the efficiency of the primitive harvester significantly drops for illumination lower than $1 \mathrm{klx}$. For applications where environmental light mainly cannot be higher than $1 \mathrm{klx}$, the bq25570-based harvester can be a better choice since the charging current of the primitive harvester can be substantially reduced. 


\section{Conclusions}

In this paper, two solar energy harvesters are introduced; the first one is a primitive harvester with very low cost; the second one is based on bq25570 IC from Texas Instruments. The two harvesters are exposed to various light conditions, and the corresponding harvested current is measured. The measured values are used to estimate the generated current corresponding to given light conditions, and these estimations are applied to the illuminations recorded at five different nodes deployed at ASWP for more than five months. The estimated current generated by both harvesters at the locations of five nodes shows their feasibility to power real-world WSN nodes deployed for environmental monitoring applications. In the worst case, both harvesters can keep the batteries charged up by only using $15 \%$ of $2000 \mathrm{mAh}$. The efficiency of the primitive harvester lies below that of the bq25570-based harvester in low light conditions but overpowers it above $3 \mathrm{klx}$ while keeping its reasonably low price. It makes the primitive harvester a feasible choice to power numerous EWSN nodes, without increasing the overall budget of the system.

Author Contributions: Conceptualization, Y.L., J.-S.L., X.L. and I.L.; methodology, Y.L., X.Z. and D.L.; validation, Y.L. and X.Z.; data curation, Y.L. and E.A.H.; writing-original draft preparation, E.A.H.; writing-review and editing, Y.L., E.A.H., D.L., J.-S.L., X.L. and I.L.; visualization, E.A.H.; supervision, I.L.; project administration, I.L.; All authors have read and agreed to the published version of the manuscript.

Funding: This research received no external funding

Acknowledgments: The authors are grateful to the Audubon Society of Western Pennsylvania (ASWP), Pittsburgh, PA, USA, for their support.

Conflicts of Interest: The authors declare no conflict of interest.

\section{References}

1. Wang, H.; Li, W.; Xu, D.; Kan, J. A Hybrid Microenergy Storage System for Power Supply of Forest Wireless Sensor Nodes. Electronics 2019, 8, 1409. [CrossRef]

2. Sharma, H.; Haque, A.; Jaffery, Z.A. Maximization of wireless sensor network lifetime using solar energy harvesting for smart agriculture monitoring. Ad Hoc Netw. 2019, 94, 101966. [CrossRef]

3. Chammas, M.; Makhoul, A.; Demerjian, J. An efficient data model for energy prediction using wireless sensors. Comput. Electr. Eng. 2019, 76, 249-257. [CrossRef]

4. Qian, J.; Jing, X. Wind-driven hybridized triboelectric-electromagnetic nanogenerator and solar cell as a sustainable power unit for self-powered natural disaster monitoring sensor networks. Nano Energy 2018, 52, 78-87. [CrossRef]

5. Gaikwad, S.; Patil, R.; Khandare, A.; Rai, A. Design WSN node for protection of forest trees against poaching based on ZigBee. In Proceedings of the 2015 IEEE International Conference on Electronics, Computing and Communication Technologies (CONECCT), Bangalore, India, 10-11 July 2015.

6. Prauzek, M.; Konecny, J.; Borova, M.; Janosova, K.; Hlavica, J.; Musilek, P. Energy harvesting sources, storage devices and system topologies for environmental wireless sensor networks: A review. Sensors 2018, 18, 2446. [CrossRef]

7. Navarro, M.; Li, Y.; Liang, Y. Energy profile for environmental monitoring wireless sensor networks. In Proceedings of the 2014 IEEE Colombian Conference on Communications and Computing (COLCOM), Bogota, Colombia, 4-6 June 2014.

8. Landsiedel, O.; Wehrle, K.; Gotz, S. Accurate prediction of power consumption in sensor networks. In Proceedings of the The Second IEEE Workshop on Embedded Networked Sensors, Sydney, Australia, 31 May 2005; EmNetS-II.

9. Tang, X.; Wang, X.; Cattley, R.; Gu, F.; Ball, A.D. Energy harvesting technologies for achieving self-powered wireless sensor networks in machine condition monitoring: A review. Sensors 2018, 18, 4113. [CrossRef]

10. Wang, H.; Jasim, A.; Chen, X. Energy harvesting technologies in roadway and bridge for different applications-A comprehensive review. Appl. Energy 2018, 212, 1083-1094. [CrossRef]

11. Verma, G.; Sharma, V. A novel thermoelectric energy harvester for wireless sensor network application. IEEE Trans. Ind. Electron. 2018, 66, 3530-3538. 
12. Geballe, T.; Hull, G. Seebeck effect in silicon. Phys. Rev. 1955, 98, 940. [CrossRef]

13. Van Herwaarden, A.; Sarro, P. Thermal sensors based on the Seebeck effect. Sens. Actuators 1986, 10, 321-346. [CrossRef]

14. Goldsmid, H.J. Introduction to Thermoelectricity; Springer: Berlin/Heidelberg, Germany, 2010; Volume 121.

15. Junior, O.A.; Maran, A.; Henao, N. A review of the development and applications of thermoelectric microgenerators for energy harvesting. Renew. Sustain. Energy Rev. 2018, 91, 376-393. [CrossRef]

16. Nguyen, N.Q.; Pochiraju, K.V. Behavior of thermoelectric generators exposed to transient heat sources. Appl. Therm. Eng. 2013, 51, 1-9. [CrossRef]

17. Wu, Y.; Yang, J.; Chen, S.; Zuo, L. Thermo-element geometry optimization for high thermoelectric efficiency. Energy 2018, 147, 672-680. [CrossRef]

18. Shaikh, F.K.; Zeadally, S. Energy harvesting in wireless sensor networks: A comprehensive review. Renew. Sustain. Energy Rev. 2016, 55, 1041-1054. [CrossRef]

19. Akhtar, F.; Rehmani, M.H. Energy replenishment using renewable and traditional energy resources for sustainable wireless sensor networks: A review. Renew. Sustain. Energy Rev. 2015, 45, 769-784. [CrossRef]

20. Penella-López, M.T.; Gasulla-Forner, M. Powering Autonomous Sensors: An Integral Approach with Focus on Solar and RF Energy Harvesting; Springer Science \& Business Media: Berlin, Germany, 2011.

21. Lu, X.; Wang, P.; Niyato, D.; Kim, D.I.; Han, Z. Wireless networks with RF energy harvesting: A contemporary survey. IEEE Commun. Surv. Tutor. 2014, 17, 757-789. [CrossRef]

22. Mishra, D.; De, S.; Jana, S.; Basagni, S.; Chowdhury, K.; Heinzelman, W. Smart RF energy harvesting communications: Challenges and opportunities. IEEE Commun. Mag. 2015, 53, 70-78. [CrossRef]

23. Mouapi, A.; Hakem, N. A new approach to design autonomous wireless sensor node based on RF energy harvesting system. Sensors 2018, 18, 133. [CrossRef]

24. Aparicio, M.P.; Bakkali, A.; Pelegri-Sebastia, J.; Sogorb, T.; Bou, V.L. Radio frequency energy harvesting-sources and techniques. Renew. Energy Util. Syst. Integr. 2016. [CrossRef]

25. Raghunathan, V.; Kansal, A.; Hsu, J.; Friedman, J.; Srivastava, M. Design considerations for solar energy harvesting wireless embedded systems. In Proceedings of the IPSN 2005. Fourth International Symposium on Information Processing in Sensor Networks, Boise, ID, USA, 15 April 2005.

26. Pimentel, D.; Musilek, P.; Knight, A.; Heckenbergerova, J. Characterization of a wind flutter generator. In Proceedings of the 2010 9th International Conference on Environment and Electrical Engineering, Prague, Czech Republic, 16-19 May 2010.

27. Roundy, S.; Steingart, D.; Frechette, L.; Wright, P.; Rabaey, J. Power Sources for Wireless Sensor Networks. In European Workshop on Wireless Sensor Network; Springer: Berlin/Heidelberg, Germany, 2004.

28. Snyman, D.B.; Enslin, J.H.R. Novel technique for improved power conversion efficiency in systems with battery back-up. Renew. Energy 1994, 4, 349-357. [CrossRef]

29. Milichko, V.A.; Shalin, A.S.; Mukhin, I.S.; Kovrov, A.E.; Krasilin, A.A.; Vinogradov, A.V.; Belov, P.A.; Simovski, C.R. Solar photovoltaics: Current state and trends. Physics-Uspekhi 2016, 59, 727. [CrossRef]

30. Ibn-Mohammed, T.; Koh, S.C.; Reaney, I.M.; Acquaye, A.; Schileo, G.; Mustapha, K.B.; Greenough, R. Perovskite solar cells: An integrated hybrid lifecycle assessment and review in comparison with other photovoltaic technologies. Renew. Sustain. Energy Rev. 2017, 80, 1321-1344. [CrossRef]

31. Li, Q.; Liu, Y.; Guo, S.; Zhou, H. Solar energy storage in the rechargeable batteries. Nano Today 2017, 16, 46-60. [CrossRef]

32. Mousavi, S.M.; Mostafavi, E.S.; Jiao, P. Next generation prediction model for daily solar radiation on horizontal surface using a hybrid neural network and simulated annealing method. Energy Convers. Manag. 2017, 153, 671-682. [CrossRef]

33. Navarro, M.; Davis, T.W.; Liang, Y.; Liang, X. ASWP: A long-term WSN deployment for environmental monitoring. In Proceedings of the 12th International Conference on INFORMATION Processing in Sensor Networks, Philadelphia, PA, USA, April 2013. [CrossRef]

34. Navarro, M.; Davis, T.W.; Liang, Y.; Liang, X. A study of long-term WSN deployment for environmental monitoring. In Proceedings of the 2013 IEEE 24th annual international symposium on personal, indoor, and mobile radio communications (PIMRC), London, UK, 8-11 September 2013.

35. Villalba, G.; Plaza, F.; Zhong, X.; Davis, T.W.; Navarro, M.; Li, Y.; Slater, T.A.; Liang, Y.; Liang, X. A networked sensor system for the analysis of plot-scale hydrology. Sensors 2017, 17, 636. [CrossRef] [PubMed] 
36. Texas Instrument. Bq25570 Nano Power Boost Charger and Buck Converter for Energy Harvester Powered Applications; Texas Instrument: Dallas, TX, USA, 2015.

37. Habtoor, M.S.; Rowaihy, H. Performance evaluation of IRIS and LOTUS motes when communicating in real environments. Int. J. Distrib. Sens. Netw. 2016, 12, 7347158. [CrossRef]

38. MICAz, Wireless Measurement System; Crossbow Technology Inc.: San Jose, CA, USA, 2006.

39. Davis, T.W.; Liang, X.; Kuo, C.M.; Liang, Y. Analysis of power characteristics for sap flow, soil moisture and soil water potential sensors in wireless sensor networking systems. IEEE Sens. J. 2012, 12, 1933-1945. [CrossRef]

40. Davis, T.W.; Liang, X.; Navarro, M.; Bhatnagar, D.; Liang, Y. An Experimental Study of WSN Power Efficiency: MICAz networks with XMesh. Spec. Issue Smart Sens. Netw. Theory Pract. Int. J. Distrib. Sens. Netw. 2012, 8, 358238. [CrossRef]

41. MDA300CA, MICA2 Data Acquistion Board; Crossbow Technology Inc.: San Jose, CA, USA, 2007.

Publisher's Note: MDPI stays neutral with regard to jurisdictional claims in published maps and institutional affiliations.

(C) 2020 by the authors. Licensee MDPI, Basel, Switzerland. This article is an open access article distributed under the terms and conditions of the Creative Commons Attribution (CC BY) license (http://creativecommons.org/licenses/by/4.0/). 